\title{
Injuries Of The Sterno-Clavicular Joint In Backpackers
}

\author{
A Shoaib, Q Mehraj, F Jepson
}

\section{A Shoaib \\ BSc(Hons) LMSSA \\ MBBS MRCSEd \\ RAMC $(\mathrm{V})$}

RMO 33 Signal Regt Specialist Registrar in Orthopaedics and

Trauma

University Hospital, Cardiff.

Email:

amershoaib@doctors.org.uk

\section{Q Mehraj}

MB chB FRCS

Locum Registrar in

Orthopaedics.

\section{F Jepson}

MBCAB MRCS Ed

Research Fellow in

Orthopaedics

Royal Preston Hospital.

\begin{abstract}
Anterior sterno-clavicular dislocation, or fracture dislocation, as a result of carrying a backpack has not previously been described. We describe two cases, and reflect on the factors that may have led to the injuries, noting that the current PLCE (personal load carrying equipment) may also increase the risk of this condition. The condition is one that carries a grading of U8 (unfit for service), and is one that Medical Officers should be aware of, as it has serious implications for a continuing military career.
\end{abstract}

\section{Introduction}

Dislocation of the sterno-clavicular joint is a rare occurrence, accounting for only $3 \%$ of all dislocations of the pectoral girdle (1). Anterior dislocation is far more common than posterior dislocation. It is normally associated with trauma, notably in road traffic accidents and on the sports field (2). Atraumatic anterior dislocations have been described, when there has not been any single traumatic event resulting in the injury (2).

Anterior dislocation or fracture dislocation as a result of carrying a large backpack has not previously been described.

Case 1

A woman of sixteen years presented with a month's history of a swelling at the sternoclavicular joint, continuous with the clavicle and forming a step at the joint (Figure 1).

She had spent most of the previous six months backpacking, carrying a large backpack for most of this time. She did not have any pain, and did not notice the lump herself, but her mother commented on it on her return. She estimated that her backpack weighed over 15 kilos.

A clinical diagnosis of anterior dislocation of the clavicle was made. She was treated conservatively with observation. At follow up, the swelling had receded and she was discharged from clinic. Three years later, she is asymptomatic, but the lump still persists.

Case 2

A woman of seventeen presented with a

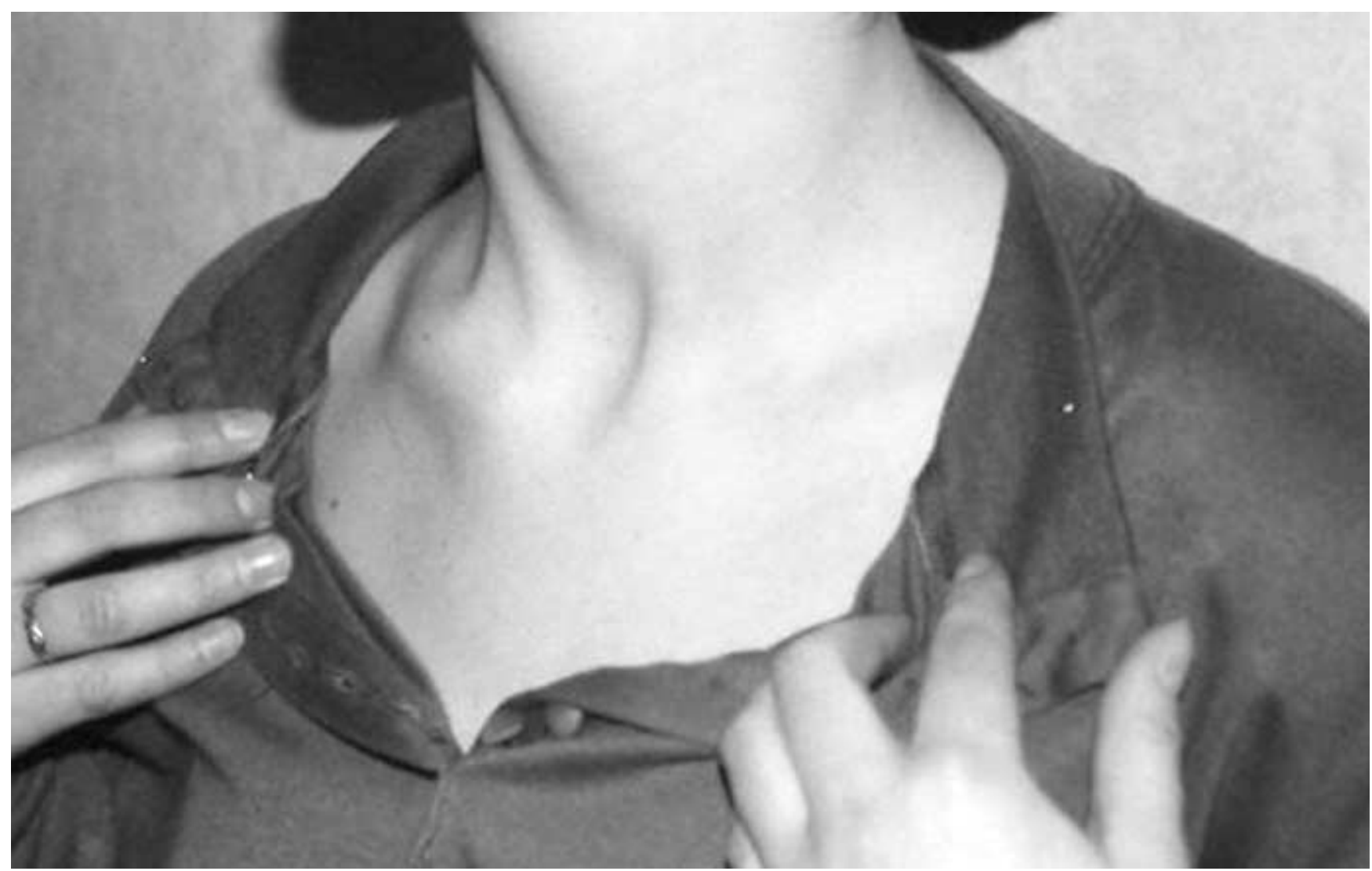




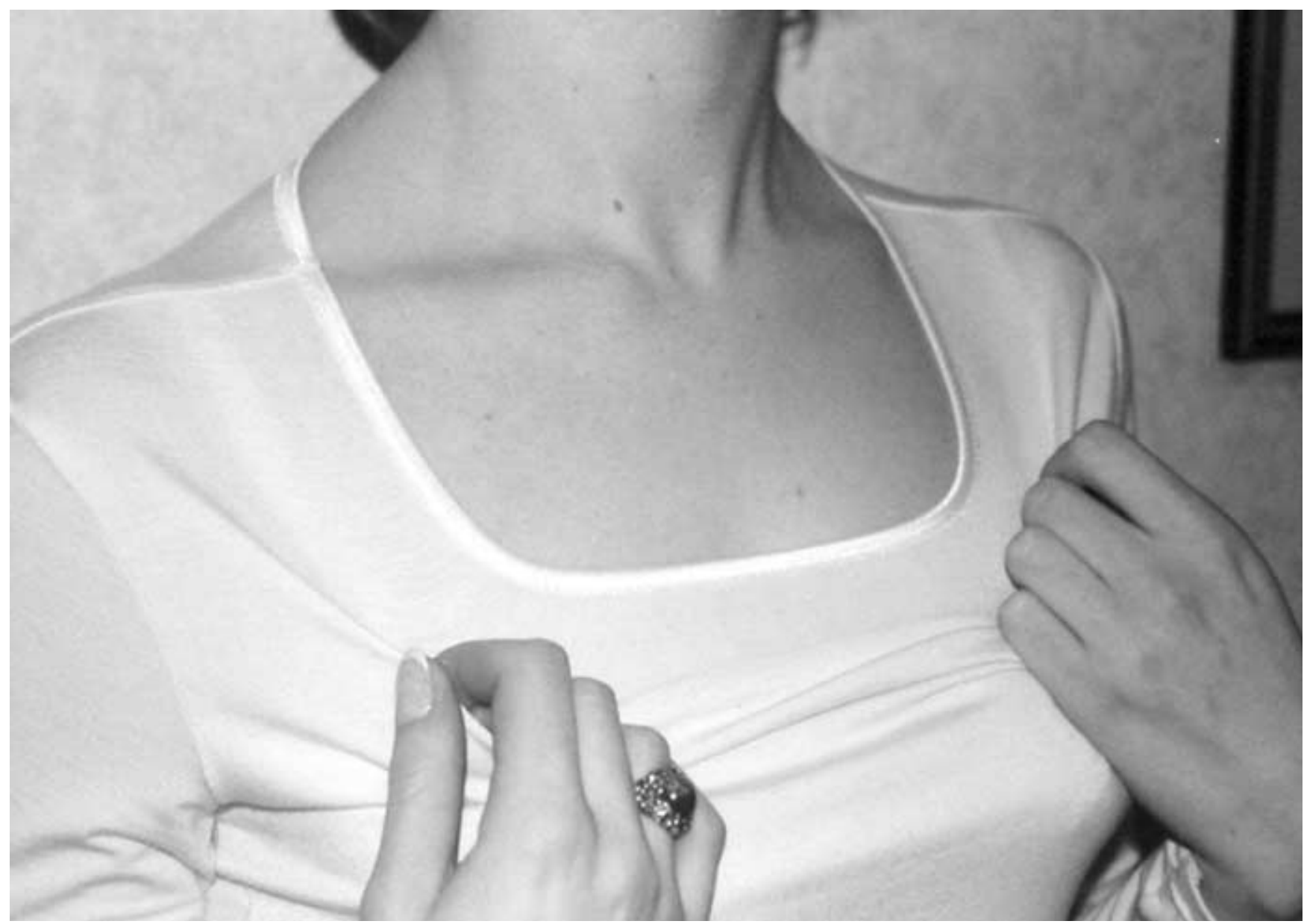

Figure 2.

similar history, having been backpacking for six months. The patient had developed tenderness over the joint while backpacking, but the tenderness had not been severe enough to curtail her trip. She did not present to a physician until her return as her symptoms were so mild. She had carried a rucksack weighing around 15 kilos.

The swelling over the sterno-clavicular joint was warm and tender and formed a step at the joint (Figure 2). A clinical diagnosis of anterior fracture disclocation of the sternoclavicular joint was confirmed by X-ray and bone scan.

The patient was treated conservatively with observation. The tenderness and swelling receded with time, but there remains a swelling three years later.

\section{Discussion}

The sterno-clavicular joint allows multidirectional mobility, but is strongly reinforced by ligamentous attachments. The posterosuperior ligament is thicker than the anterior ligament. There is also a strong costoclavicular ligament and an interclavicular ligament.

The forces required to dislocate the joint are relatively large (3). Indeed, some authors have warned that an erroneous diagnosis of dislocation is often given when, in fact, there is a medial epiphyseal fracture (4). This is because the medial epiphysis commonly does not fuse with the metaphysis until the age of
25 years and may not be complete before 31 years (5).

A review of the literature reveals that the majority of anterior dislocations are due to an indirect force (6). The costoclavicular ligament acts as a fulcrum, and when the lateral end of the clavicle is forced backwards, and the medial end is levered anteriorly.

The injuries in these patients are unusual because of the nature of the mechanism of injury. This may be because of persistent posterior force on the lateral third of the clavicle from shoulder straps. In addition, patient 2 had loose shoulder straps, which allow repeated rapid loading and unloading of the clavicle during walking, culminating in a stress fracture.

The manufacturers' guidelines advise that backpack purchasers should bear the majority of the weight of the backpack on the iliac crest using the waist band (7). The shoulder straps should be used primarily as stabilisers and carry only $25 \%$ of the weight. Poor pressure distribution in the shoulder straps can result in point loading if the backpack is incorrectly fitted. Commercially available backpacks aim to optimise the fit by offering a range of sizes of fixed geometry systems, or by offering an adjustable geometry system. They also offer different fits for men and women.

The popularity of backbacking for extended periods as a leisure activity may result in 
an increase in the frequency of this injury. The use of 'one size fits all' backpacks in the military environment may also increase the risk of this injury. Military backpacks do not offer different fits for the two sexes, and have no adjustment possible in length.

Medical Officers should be aware of the possibility of this injury and its implications. For new entrants, it automatically carries the grading of U8 (8) (Unfit for service). Treatment is generally conservative with clavicular figure of eight strapping, after closed reduction if required, and rest to allow union or healing. Conservative therapy may not resolve the underlying mechanical problem, and resumption of normal duties may result in a recurrence of the injury, if the wearing of a backpack is required. Open reduction and internal fixation is a hazardous procedure for chronic dislocations, as there are many vital structures in close proximity.

\section{Conclusion}

Anterior sterno-clavicular dislocation or fracture dislocation is possible as a result of a poorly fitted backpack. Medical Officers should be aware of the condition for diagnosis, and the implications for a military career.

\section{References}

1. Cave EF, ed. Fractures and other Injuries. Chicago: Year Book Medical Publishers Inc, 1958: 258.

2. Rockwood CA, Odor JM. Spontaneous Atraumatic Anterior Subluxation of the Sternoclavicular Joint. FBFS 1989; 71A(9):1280-1288.

3. Beam JG. Direct Observation on the Function of the Capsule of the Sternoclavicular Joint in Clavicular Support. F Anat 1967; 101:159-170.

4. Rockwood CA, Matsen FA, eds. The Shoulder . WB Saunder Co, Philadelphia, 1990: 482.

5. Webb PAO, Suchey JMM. Epiphyseal Union of the Anterior Iliac Crest and the Medial Clavicle in a modern multiracial sample of American males and females. Am $\mathcal{F}$ Phys Anthropol 1985; 68: 457-466.

6. Nevasier JS. Injuries of the Clavicle and Its articulations. Orthop Clin N Am 1980; 11(2): 233237.

7. Retailers Reference Manual. Berghaus Ltd, 1997.

8. PULHHEEMS - A Joint Service System of Medical Classification (JSP 346), 2000. 